\title{
Production of Scenedesmus almeriensis Using Pilot-Scale Raceway Reactors Located inside a Greenhouse
}

\author{
Ainoa Morillas-España ${ }^{1,2}$, Silvia Villaró ${ }^{1,2}$, Martina Ciardi ${ }^{1,2}$, Gabriel Acién ${ }^{1,2}$ (D) and Tomás Lafarga ${ }^{1,2, *(D)}$ \\ 1 Department of Chemical Engineering, University of Almería, 04120 Almería, Spain; ame778@ual.es (A.M.-E.); \\ svc547@inlumine.ual.es (S.V.); martina.ciardi@studio.unibo.it (M.C.); facien@ual.es (G.A.) \\ 2 CIESOL Solar Energy Research Centre, Joint Centre University of Almería-CIEMAT, 04120 Almería, Spain \\ * Correspondence: lpt365@ual.es
}

check for updates

Citation: Morillas-España, A.; Villaró, S.; Ciardi, M.; Acién, G.; Lafarga, T.

Production of Scenedesmus almeriensis Using Pilot-Scale Raceway Reactors Located inside a Greenhouse. Phycology 2022, 2, 76-85. https:// doi.org/10.3390/phycology2010005

Academic Editor: Peer Schenk

Received: 24 November 2021

Accepted: 10 January 2022

Published: 12 January 2022

Publisher's Note: MDPI stays neutral with regard to jurisdictional claims in published maps and institutional affiliations.

Copyright: (C) 2022 by the authors. Licensee MDPI, Basel, Switzerland. This article is an open access article distributed under the terms and conditions of the Creative Commons Attribution (CC BY) license (https:// creativecommons.org/licenses/by/ $4.0 /)$.

\begin{abstract}
The microalga S. almeriensis was produced in spring and summer using $80 \mathrm{~m}^{2}$ raceway reactors located inside a greenhouse in Almería, Spain. This microalga was selected because it is a fast-growing and robust strain with potential applications in the production of functional foods and feeds or as a high-value agricultural biostimulant. Overall, the biomass productivity obtained in summer was $24.9 \pm 0.9 \mathrm{~g} \cdot \mathrm{m}^{-2} \cdot$ day $^{-1}$. This value was higher than that obtained in spring, with an average value of $21.4 \pm 1.3 \mathrm{~g} \cdot \mathrm{m}^{-2} \cdot$ day $^{-1}(p<0.05)$. The $\mathrm{F}_{\mathrm{v}} / \mathrm{F}_{\mathrm{m}}$ value of the cultures at the stationary phase was comparable and around 0.6 , which is the optimum of this strain. No major differences in the macromolecular composition of the biomass were observed between seasons, with an average protein, lipid, ash, and carbohydrate content of 37.9, 4.6, 10.8, and 46.7\%, respectively. The data reported herein were used to validate a previously described model. The differences between the experimental and the predicted biomass productivities were below $5 \%$ in spring and $8 \%$ in summer, although a larger dataset is needed to validate the model. Overall, results supported the robustness of the selected strain and its utilisation in different industrial sectors.
\end{abstract}

Keywords: microalgae; photobioreactor; agricultural products; waste management; circular economy; biotechnology; wastewater; pig slurry

\section{Introduction}

Microalgae are gaining increased importance in the context of global bioeconomy. These microorganisms are mainly being used as foods or nutraceuticals [1]. However, despite the large number of microalgal strains currently available in culture collections, only a limited number of strains are being mass cultured for industrial applications. These include, but are not limited to, Arthrospira platensis and Chlorella vulgaris used as food [2] or Dunaliella salina and Haematococcus pluvialis which are commercially produced as sources of $\beta$-carotene and astaxanthin, respectively [3-5]. Microalgal strains used as food in the EU must comply with Regulation (EU) 2015/2283 on novel foods. Due to their long history of use, A. platensis (commercially known as spirulina) and C. vulgaris do not need to comply with this regulation. Other strains such as Tetraselmis chuii can also be used as food in the EU [6]. In the United States, the consumption of microalgae is regulated by the Food and Drug Administration (FDA), which recognise food additives and ingredients as GRAS, the acronym for the phrase "generally recognised as safe". Arthrospira, Chlorella, Dunaliella, Haematococcus, Schizochytrium, Porphyridium cruentum, and Crypthecodinium cohnii have GRAS status [7]. Most countries accept the consumption of microalgae following the FDA recommendations. Microalgae are used to produce food not only directly as food ingredients but also indirectly, as feed ingredients [8] or as high-value agricultural products, namely biostimulants and biopesticides [9]. Due to their high content in proteins and other valuable bioactive molecules, microalgae are excellent sources of feed ingredients. In addition, biostimulants are one of the top trends in agriculture, especially in organic 
cropping systems. The biostimulant activity of microalgae is due to their content of phytohormones (e.g., auxins, cytokinines, ethylene, gibberellins) [10].

Due to their small size, microalgae are not harvested from the environment but are produced in controlled facilities using photobioreactors. The most widely used photobioreactor designs are raceway reactors. Today, approximately $90 \%$ of the microalgal biomass being commercialised is produced using raceway reactors [11]. Their main advantages are their simplicity, ease of scale-up, and low construction costs. Indeed, raceway reactors are the most cost-effective cultivation system and their low productivity is compensated by their low capital and operating costs (and high economic value of microalgae) [12]. One of the main challenges of microalgae production is the difficulty of up-scaling biological processes. Most of the studies conducted to date assessed biomass productivities using laboratory-scale or pilot-scale photobioreactors that are not representative of industrial practices. There is an urgent need for up-scaling microalgae production processes to predict industrial productivities and estimate production costs.

The aim of this study was to validate the production of the strain Scenedesmus almeriensis using $80 \mathrm{~m}^{2}$ raceway photobioreactors during two seasons, spring and summer. S. almeriensis was selected because of its huge potential to achieve commercial success. Due to its high content in lutein, this strain has been suggested as a potential functional food ingredient [13]. This microalga also showed potential for use as a feed ingredient promoting the gut functionality of fish [8] and as a biostimulant in agriculture [9]. In addition, S. almeriensis is a robust strain that can be produced using wastewater and different reactor designs $[14,15]$ which has been suggested as key to reduce production costs [16].

\section{Materials and Methods}

\subsection{Microalga Used and Culture Media Composition}

The selected strain was S. almeriensis (CCAP 276/24). The strain S. almeriensis was initially isolated from a photobioreactor exposed to high temperature $\left(45^{\circ} \mathrm{C}\right)$ and irradiance $\left(2000 \mu \mathrm{mol} \cdot \mathrm{m}^{-2} \cdot \mathrm{s}^{-1}\right)$ conditions [17]. Previous reports demonstrated that $S$. almeriensis can adapt to $\mathrm{pH}$, temperature, and salinity values ranging from $7-10,26-40{ }^{\circ} \mathrm{C}$, and $0-5 \mathrm{~g} \mathrm{NaCl} \cdot \mathrm{L}^{-1}$, respectively. Moreover, the used strain shows no signs of photoinhibition up to $1625 \mu \mathrm{mol} \cdot \mathrm{m}^{-2} \cdot \mathrm{s}^{-1}$ [18].

The inocula of S. almeriensis were produced at $23 \pm 2{ }^{\circ} \mathrm{C}, \mathrm{pH} 8.0 \pm 0.1$, and $150 \mu \mathrm{mol} \cdot \mathrm{m}^{-2} \cdot \mathrm{s}^{-1}$ in batch mode until a concentration of $1 \mathrm{~g} \cdot \mathrm{L}^{-1}$. Then, the inocula were scaled up to a final volume of $80 \mathrm{~L}$ using $\mathrm{pH}$-controlled outdoor bubble column photobioreactors placed inside a greenhouse. The culture medium was formulated using commercial fertilisers instead of analytical-grade chemicals. The composition of the medium was $0.90 \mathrm{~g} \cdot \mathrm{L}^{-1} \mathrm{NaNO}_{3}, 0.18 \mathrm{~g} \cdot \mathrm{L}^{-1} \mathrm{MgSO}_{4}, 0.14 \mathrm{~g} \cdot \mathrm{L}^{-1} \mathrm{~K}_{2} \mathrm{PO}_{4}$, and $0.03 \mathrm{~g} \cdot \mathrm{L}^{-1}$ Karentol $^{\circledR}$ (Konegard, Barcelona, Spain). Karentol ${ }^{\circledR}$ is a commercial solid mixture of micronutrients that include boron, copper, iron, manganese, molybdenum, and zinc.

\subsection{Photobioreactors Used}

The biomass production was conducted using three $80 \mathrm{~m}^{2}$ raceway reactors located inside a greenhouse (Figure 1) at the Institute for Agricultural and Fisheries Research and Training (IFAPA) in Almería, Spain. The three reactors were identical and were operated simultaneously under the same environmental conditions (Figure 2). The operating volume of the reactors was $11.8 \mathrm{~m}^{3}$ and the depth of the culture was $0.13 \mathrm{~m}$. Biomass production was initially conducted in batch mode until the stationary phase was achieved and then in semi-continuous mode with a dilution rate of 0.3 day $^{-1}$, which is the optimum for these reactors in spring and summer [19]. Semi-continuous production was conducted for 20 days. Temperature, $\mathrm{pH}$, and dissolved oxygen concentration were monitored using $5083 \mathrm{~T}$ and 5120 probes (Crison Instruments, Barcelona, Spain) connected to an MM44 control-transmitter unit (Crison Instruments, Barcelona, Spain) and Labview data acquisition software (National Instruments, Austin, TX, USA). 


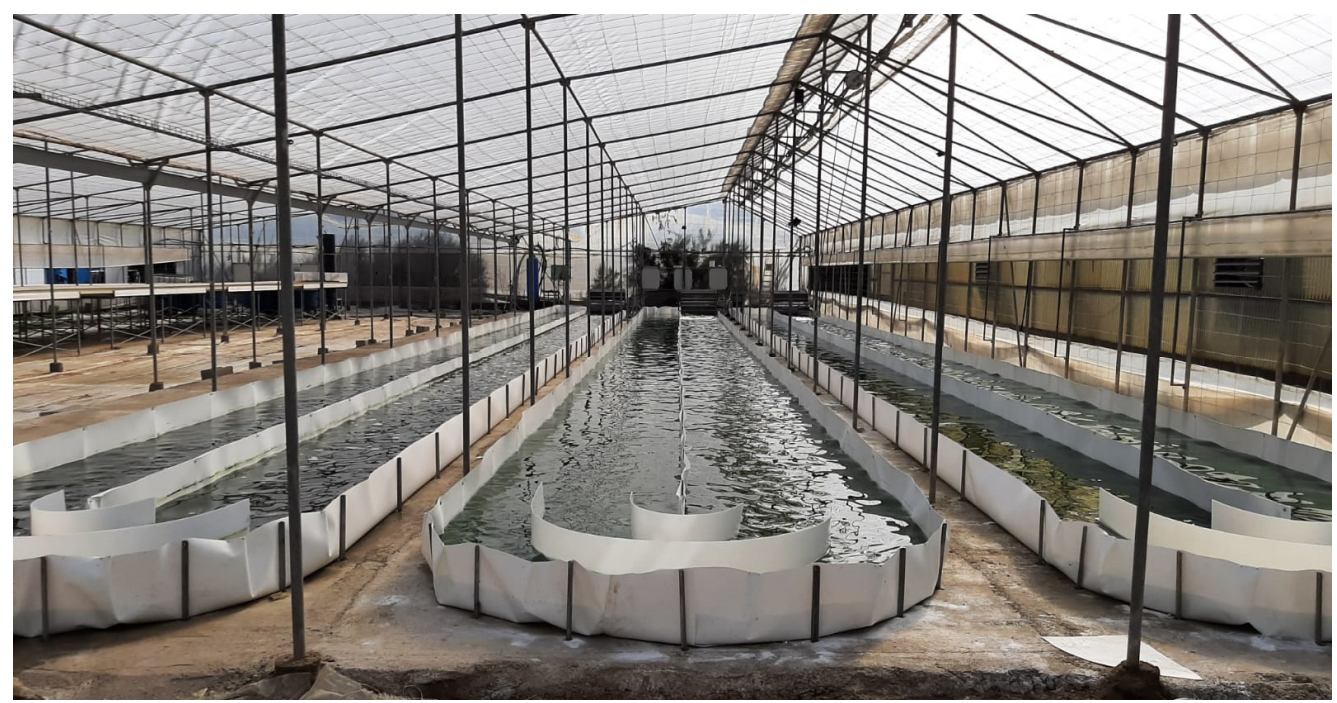

Figure 1. Photobioreactors used.

(A)

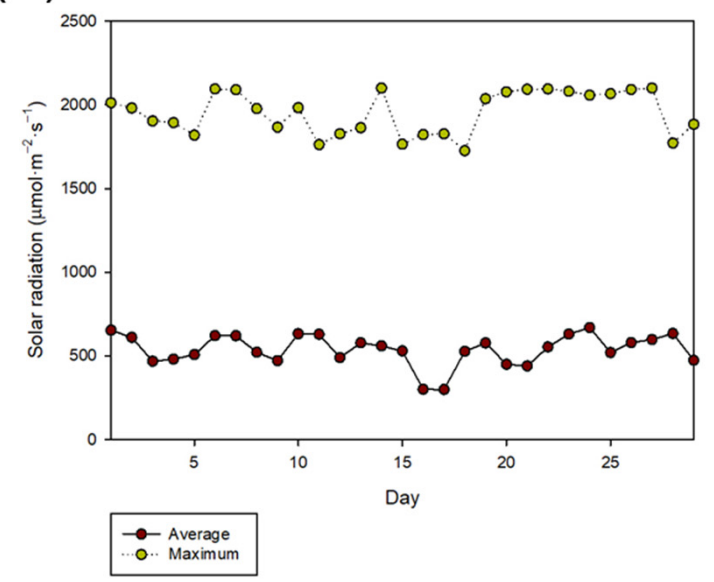

(C)

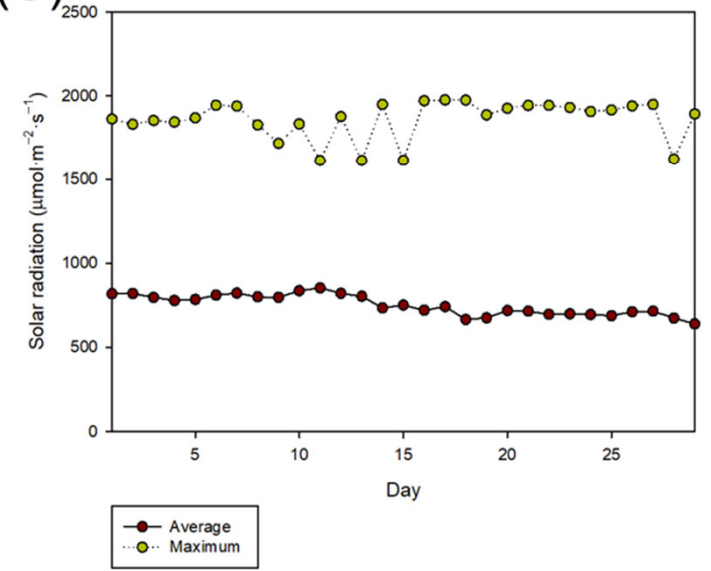

(B)

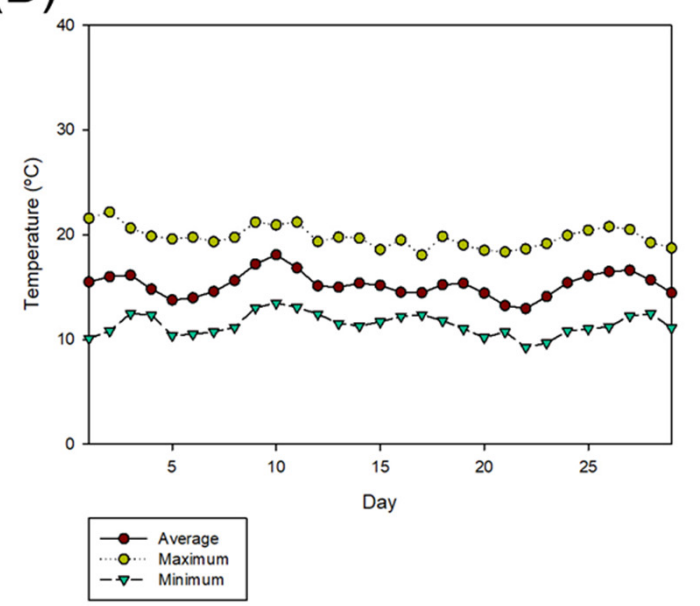

(D)

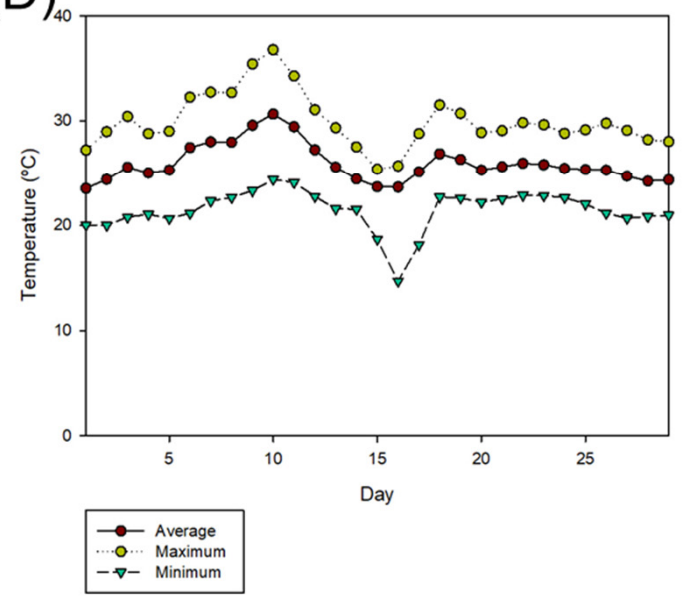

Figure 2. (A) Solar radiation and (B) temperature during biomass production in spring and (C) solar radiation and $(\mathbf{D})$ temperature during biomass production in summer.

The $\mathrm{pH}$ was controlled and kept constant at $8.0 \pm 0.1$ by on-demand injection of carbon dioxide. Water evaporation was compensated daily by addition of freshwater. The culture was harvested using an industrial SSD 6-06-007 GEA separator (GEA Westfalia Group, 
Oelde, Germany). The harvested biomass was immediately frozen and freeze-dried. The dried powder was vacuum-sealed and stored at $-20^{\circ} \mathrm{C}$ until further analysis. The nutrient content of the water effluent was analysed to ensure that the culture was not limited in terms of nutrients.

\subsection{Analytical Determinations}

The biomass concentration was measured by dry weight filtering $50 \mathrm{~mL}$ of culture through $1 \mu \mathrm{m}$ filters and drying it in an oven at $80^{\circ} \mathrm{C}$ for $24 \mathrm{~h}$. The biomass productivity was calculated as the product of the biomass concentration and the dilution rate. The chlorophyll fluorescence ratio $\left(\mathrm{F}_{\mathrm{v}} / \mathrm{F}_{\mathrm{m}}\right)$ was determined using an AquaPen AP 100 fluorometer (Photon System Instruments, Drásov, Czech Republic) after a dark adaptation period of 5 min.

The biomass extinction coefficient $\left(K_{a}\right)$ and the average irradiance inside the culture $\left(I_{a v}\right)$ were calculated as described previously [19]. Spectrophotometric determinations were conducted using a Genesys ${ }^{\mathrm{TM}} 10 \mathrm{~S}$ UV-Vis spectrophotometer (Thermo Fisher Scientific, Barcelona, Spain).

The lipids were extracted following the Folch method using chloroform:methanol $(2: 1 \mathrm{v} / \mathrm{v})$ as the solvent and the total lipid content was calculated gravimetrically [20]. The crude protein content was determined by the Kjeldahl method following acid digestion using a nitrogen-to-protein conversion factor of 5.95 [21]. The ash content was determined

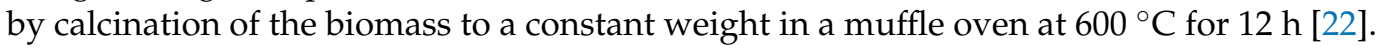
The carbohydrate content was determined by difference.

The pigment contents, namely chlorophyll-a $\left(C h_{a}\right)$, chlorophyll-b $\left(C h_{b}\right)$, and total carotenoids $(T C)$, were estimated spectrophotometrically using the equations proposed by Wellburn [23]. Briefly, $100 \mathrm{mg}$ of freeze-dried biomass were suspended in $40 \mathrm{~mL}$ of acetone and sonicated for $10 \mathrm{~s}$ using a UP400S ultrasonic processor (Hielscher Ultrasonics $\mathrm{GmbH}$, Teltow, Germany) operating at $400 \mathrm{~W}$ and $24 \mathrm{kHz}$. The extract was stirred at 150 rpm for $5 \mathrm{~min}$ and centrifuged. The supernatant was evaporated under a nitrogen stream, resuspended in methanol, and the pigment concentration was calculated using:

$$
\begin{gathered}
\mathrm{Ch}_{a}\left(\mathrm{mg} \cdot \mathrm{L}^{-1}\right)=16.72 \cdot A_{665}-9.16 \cdot A_{652} \\
\mathrm{Ch}_{b}\left(\mathrm{mg} \cdot \mathrm{L}^{-1}\right)=34.09 \cdot A_{652}-15.28 \cdot A_{665} \\
\mathrm{TC}\left(\mathrm{mg} \cdot \mathrm{L}^{-1}\right)=\frac{1000 \cdot A_{470}-1.63 \cdot \mathrm{Ch}_{a}-104.96 \cdot \mathrm{Ch}_{b}}{221}
\end{gathered}
$$

where $A_{665}, A_{652}$, and $A_{470}$ are the optical density of the extract at 665,652 , and $470 \mathrm{~nm}$, respectively. Two technical replicates were conducted per natural replicate and results are expressed on a dry weight basis.

The concentration of $\mathrm{N}-\mathrm{NO}_{3}{ }^{-}$and $\mathrm{P}_{-} \mathrm{PO}_{4}{ }^{3-}$ at the inlets and outlets of the reactors was measured using official methods approved by the Spanish Ministry of Agriculture [24]. Briefly, $\mathrm{N}-\mathrm{NO}_{3}{ }^{-}$and $\mathrm{P}-\mathrm{PO}_{4}{ }^{3-}$ were measured spectrophotometrically by measuring the absorbance at 220-275 nm and the phospho-vanado-molybdate complex, respectively. All these determinations were conducted daily and in triplicate per natural replicate.

\subsection{Model Validation}

Experimental results were compared to those predicted by a recently published model developed following a surface response methodology [25]. The model allows predicting biomass productivity in raceway reactors as a function of the dilution rate and the depth of the culture. The model enables the estimation of the biomass productivity in the south of spain in spring using the following equation:

$$
P_{b}\left(\mathrm{~g} \cdot \mathrm{m}^{-2} \cdot \mathrm{day}^{-1}\right)=5.90+113.41 \cdot \mathrm{D}-47.82 \cdot h-145.43 \cdot D^{2}
$$


In summer, biomass productivity can be estimated using the following equation:

$$
P_{b}\left(\mathrm{~g} \cdot \mathrm{m}^{-2} \cdot \mathrm{day}^{-1}\right)=-0.23+149.57 \cdot \mathrm{D}-6.73 \cdot h-192.00 \cdot D \cdot h-142.74 \cdot D^{2}
$$

where $D$ is the dilution rate $\left(\right.$ day $\left.^{-1}\right)$ and $h$ is the depth of the culture (m).

\subsection{Statistical Analysis}

Normality and homoscedasticity of the variables within each group were checked. The data were analysed using one-way analysis of variance with JMP 13 (SAS Institute Inc., Cary, NC, USA). A Tukey pairwise comparison of the means was carried out to identify where sample differences occurred $(p<0.05)$.

\section{Results}

The environmental conditions during biomass production are shown in Figure 2. Briefly, the average environmental temperature during spring and summer was $15.2 \pm 1.1$ and $25.9 \pm 1.7^{\circ} \mathrm{C}$, respectively. Maximum temperature values were on average $19.3 \pm 1.6$ and $29.3 \pm 2.6^{\circ} \mathrm{C}$, respectively. Similarly, the average solar radiation that reached the cultures in spring and summer was $559 \pm 82$ and $741 \pm 64.4 \mu \mathrm{mol}$ photons $\cdot \mathrm{m}^{-2} \cdot \mathrm{s}^{-1}$, respectively.

These environmental conditions allowed achieving biomass productivities of $21.4 \pm 1.3$ and $24.9 \pm 0.9 \mathrm{~g} \cdot \mathrm{m}^{-2}$. day ${ }^{-1}$ in spring and summer, respectively (Figure 3 ). $F_{\mathrm{v}} / \mathrm{F}_{\mathrm{m}}$ values were comparable in both seasons and around 0.6 , which is the optimum for S. almeriensis produced in raceway reactors.

(A)

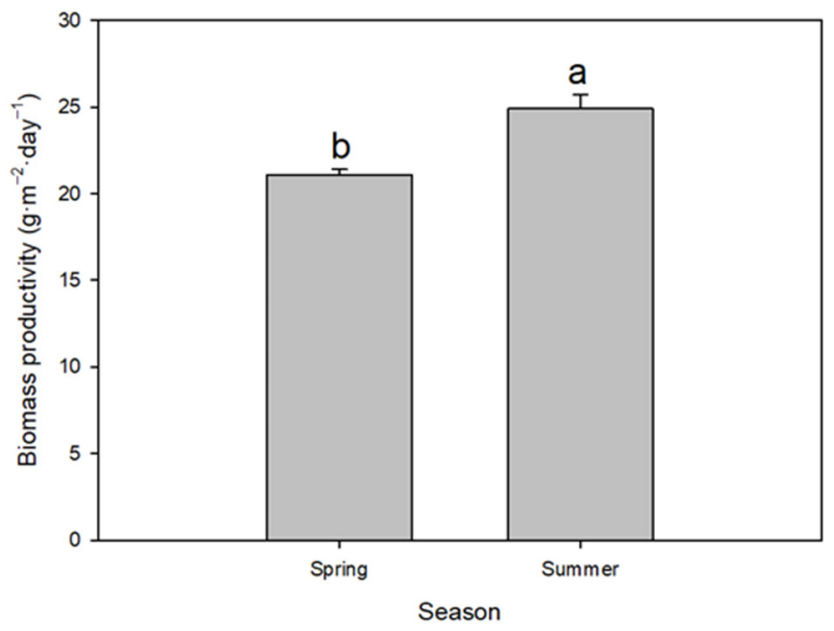

(B)

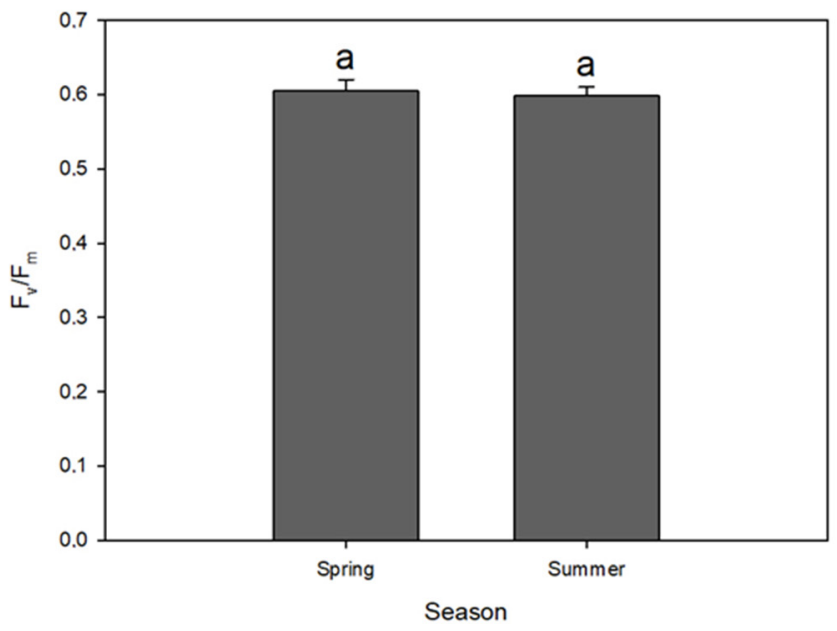

Figure 3. (A) Biomass productivity and (B) $\mathrm{F}_{\mathrm{v}} / \mathrm{F}_{\mathrm{m}}$ values during the steady state. Values represent the means of three independent determinations \pm SD. Different letters indicate significant differences between seasons. The criterion for statistical significance was $p<0.05$.

The biomass productivity values were compared to those obtained using a model that predicts biomass productivities as a function of culture depth and the dilution rate [25]. The comparison between the experimental and predicted biomass productivity values is shown in Figure 4. The model used was developed using wastewater instead of freshwater and commercial fertilisers as the nutrient sources. Overall, the differences between the experimental and predicted biomass productivity values were around $5 \%$ in spring and $8 \%$ in summer, suggesting the validity of the model to predict biomass productivity in the south of Spain.

The macromolecular composition of the produced biomass is summarised in Table 1. Overall, no major differences were observed between the composition of the biomass produced in spring or in summer. The protein content of the biomass was on average $37.9 \%$. 
The lipid and ash contents were calculated as 4.6 and 10.8\%, respectively. Moreover, no differences were observed between the total chlorophyll content of the biomass produced in spring and summer $\left(9.9 \pm 0.3 \mathrm{mg} \cdot \mathrm{g}^{-1}\right)$. However, the total carotenoid content in summer was estimated as $3.9 \pm 0.5 \mathrm{mg} \cdot \mathrm{g}^{-1}$, higher than that obtained in spring with an average value of $2.5 \pm 0.2 \mathrm{mg} \cdot \mathrm{g}^{-1}(p<0.05)$.

Table 1. Macromolecular composition of S. almeriensis. Results are the average of three independent determinations \pm SD. Different letters indicate significant differences. The criterion for statistical significance was $p<0.05$.

\begin{tabular}{ccccc}
\hline Season & Protein $\left(\mathbf{g} \cdot \mathbf{1 0 0} \mathbf{g}^{-\mathbf{1}}\right)$ & Lipid $\left(\mathbf{g} \cdot \mathbf{1 0 0} \mathbf{g}^{-\mathbf{1})}\right.$ & Ash $\left(\mathbf{g} \cdot \mathbf{1 0 0} \mathbf{g}^{-\mathbf{1}}\right)$ & $\begin{array}{c}\text { Carbohydrate } \\
\left(\mathbf{g} \cdot \mathbf{1 0 0} \mathbf{g}^{-\mathbf{1}} \mathbf{)}\right.\end{array}$ \\
\hline Spring & $38.0 \pm 0.2$ & $4.6 \pm 0.3$ & $9.9 \pm 0.3$ & $47.5 \pm 0.7$ \\
Summer & $37.8 \pm 0.4$ & $4.6 \pm 0.5$ & $11.6 \pm 2.4$ & $45.9 \pm 2.5$ \\
\hline
\end{tabular}
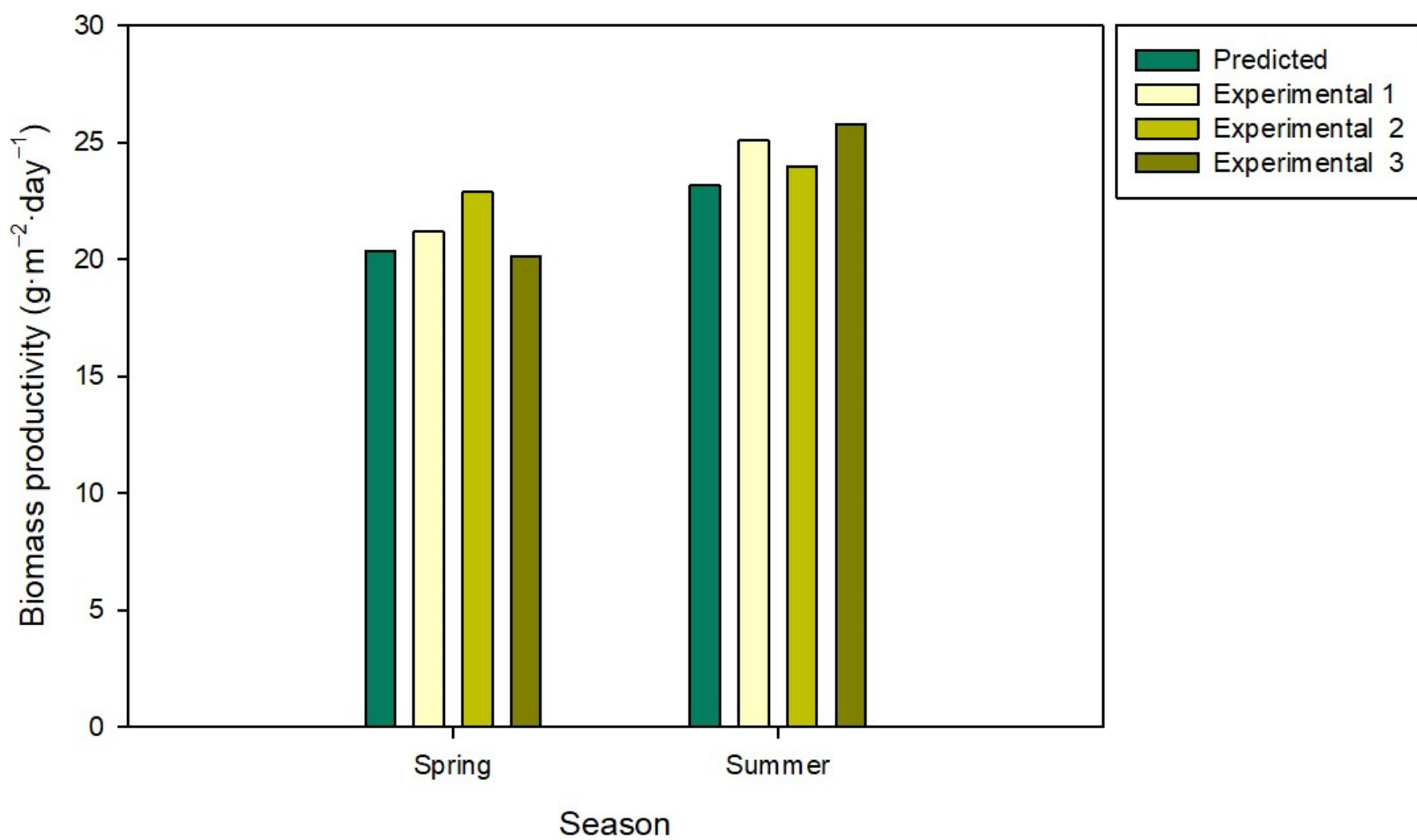

Figure 4. Differences between predicted and experimental biomass productivities. Predicted values were obtained using an SRM model for spring and summer, respectively [25].

\section{Discussion}

The environmental conditions of the region during biomass production and the design of the photobioreactor allowed achieving biomass productivity values of $21.4 \pm 1.3$ and $24.9 \pm 0.9 \mathrm{~g} \cdot \mathrm{m}^{-2} \cdot$ day $^{-1}$ in spring and summer, respectively. The higher productivity obtained in summer can be attributed to more favourable environmental conditions. Indeed, the optimal temperature for S. almeriensis is $25^{\circ} \mathrm{C}$ [18] and the average temperature in summer was $25.9^{\circ} \mathrm{C}$. The biomass productivity of the process has a striking effect on the production cost of the biomass and it is highly sensitive to geospatial factors [12]. The productivity values reported here were in line with those obtained in previous reports using raceway reactors. For example, the biomass productivity of a $100 \mathrm{~m}^{2}$ raceway reactor operated at a culture depth of $0.1 \mathrm{~m}$ and a dilution rate of $0.2-0.3$ day $^{-1}$ in spring led to a 
biomass productivity of 20-25 $\mathrm{g} \cdot \mathrm{m}^{-2} \cdot$ day $^{-1}$ [26]. Similarly, biomass productivity values from 20 to $25 \mathrm{~g} \cdot \mathrm{m}^{-2}$. day ${ }^{-1}$ were reported for a $80 \mathrm{~m}^{2}$ raceway reactor during spring and summer [19]. Similarly, the biomass productivity values reported herein were also comparable to those obtained when producing microalgae using wastewater and other waste streams instead of freshwater. For example, the productivity of a $32 \mathrm{~m}^{2}(0.12 \mathrm{~m}$ culture depth) raceway reactor producing Scenedesmus sp. in summer was $24 \mathrm{~g} \cdot \mathrm{m}^{-2} \cdot$ day $^{-1}$ when operated using centrate from anaerobic digestion as the sole nutrient source and a dilution rate of 0.3 day $^{-1}$ [27]. Similarly, a previous study utilising the same photobioreactor used herein but operated with wastewater instead of freshwater reported maximum biomass productivities of $25.1 \mathrm{~g} \cdot \mathrm{m}^{-2} \cdot$ day $^{-1}$ in summer [14]. The results demonstrate the robustness of the produced strain that can grow well independently of the type of water used. Economic viability is of key importance to achieve commercial success [28]. Annual studies are needed to assess the techno-economic performance of the reactors. However, production of microalgal biomass using raceway reactors is feasible as most of the biomass produced today is produced using this system [16].

The quantum yield or the $F_{v} / F_{m}$ value of the cultures was monitored daily. The $F_{v} / F_{m}$ value, shown in Figure 2, represents a non-invasive measurement of photosystem II (PSII) activity [29]. A decrease in the quantum yield indicates that the culture is subjected to a stress condition such as excess light [30], lack of nutrients [31], or presence of toxins or heavy metals [32]. The $F_{v} / F_{m}$ values are just an estimation of the status of the culture. The optimal value for most microalgal strains ranges from 0.6 to 0.7 . Previous studies reported decreased $\mathrm{F}_{\mathrm{v}} / \mathrm{F}_{\mathrm{m}}$ values in summer because of reversible damage to PSII components [33]. Values close to 0.6 have been reported for this same strain in spring and summer, demonstrating that the microalgae were growing without stress conditions. S. almeriensis is highly resistant to harsh environments, especially in terms of solar radiation [18].

In the present study, the biomass productivity obtained when operating the reactors in spring and summer was compared with that predicted using a recently published model based on a response surface methodology [25]. A response surface methodology explores the relationship between several explanatory variables and one or more response variables. In the used model, the explanatory variables used were the dilution rate and the depth of the culture, which are the main operational parameters in raceway reactors [34]. Moreover, because of the strong impact of environmental conditions on the performance of microalgae, the above-mentioned study developed one model for each season. This is a simple model to predict biomass productivity based only on operational conditions, other aspects related to the biology of microalgae and environmental conditions would better predict biomass productivity [35,36]. In the present study, the difference between the predicted and experimental values was lower than $5 \%$ in spring and $8 \%$ in summer, suggesting the validity of the model. It is important to highlight that a larger dataset is needed to confirm these findings.

The effect of environmental conditions on the macromolecular composition of the produced biomass is shown in Table 1 . The composition of the biomass can be strongly affected by environmental and operational conditions [34,37]. The median macromolecular composition of microalgae was reported to be $32.2 \%$ protein, $17.3 \%$ lipid, $15.0 \%$ carbohydrate, $17.3 \%$ ash, and $5.7 \%$ RNA [38]. These values were calculated using a hierarchical Bayesian analysis of data compiled from the literature. In the present study, as highlighted before, no differences were observed in the protein, lipid, ash, and carbohydrate content of the produced biomass. The composition of the produced biomass was comparable to that of Scenedesmus sp. produced in controlled laboratory-scale photobioreactors [39]. The protein content of the produced biomass was around $38 \%$, which compares well with other food products rich in protein such as legumes (approximately 26\%). Although the protein content of the biomass was high, other microalgae have higher protein content. For example, the cyanobacterium A. platensis or spirulina can accumulate over $60 \%$ of protein on a dry weight basis [40]. A. platensis is a prokaryotic cyanobacterium and not a eukaryotic microalga. Cyanobacteria have a higher protein content than microalgae [38]. 
Moreover, despite not affecting the total chlorophyll content, the different environmental conditions during the two production periods promoted the synthesis and accumulation of carotenoids. In the present study, only the total carotenoid content was determined. Further studies will identify the carotenoid profile of the biomass, focusing on lutein which has anti-inflammatory properties and other beneficial effects, especially on eye health [41]. Carotenoids are ubiquitous and essential pigments in photosynthesis. These compounds absorb in the blue-green region of the solar spectrum and transfer the absorbed energy to chlorophylls. By doing this, they expand the wavelength range of light that is able to drive photosynthesis and are therefore of key importance for photosynthetic organisms. The higher solar radiation values in summer probably triggered the synthesis and accumulation of carotenoids. Other microalgae such as $H$. pluvialis respond similarly to high light availability and promote the synthesis and accumulation of carotenoids and, in the case of H. pluvialis, astaxanthin [5]. As highlighted above, S. almeriensis shows potential for being used as an ingredient in the development of functional foods because of its high content in lutein. Although some food products have been developed [13,42], S. almeriensis is not yet permitted as food. Further studies will assess the safety of the produced biomass and will facilitate the incorporation of this valuable microalga into foods.

\section{Conclusions}

The microalga $S$. almeriensis can be scaled up using raceway reactors and commercial fertilisers as the sole nutrient source. Biomass productivities were comparable to those of previous studies using similar photobioreactor designs. An increase in biomass productivity in summer was observed when compared to spring because of more favourable environmental conditions. The composition of the produced biomass suggests the potential of $S$. almeriensis as a novel food or feed ingredient because of its high protein content, which compares favourably with current protein sources such as soybean.

Author Contributions: Conceptualisation, T.L. and G.A.; formal analysis, A.M.-E., S.V. and M.C.; investigation, A.M.-E., S.V. and M.C.; writing — original draft preparation, A.M.-E. and S.V.; writing—review and editing, T.L.; funding acquisition, G.A. and T.L. All authors have read and agreed to the published version of the manuscript.

Funding: This research was funded by the EU H2020 Research and Innovation Programme, grant number 727874 .

Institutional Review Board Statement: Not applicable.

Informed Consent Statement: Not applicable.

Data Availability Statement: All of the data is contained within the article.

Conflicts of Interest: The authors declare no conflict of interest.

\section{References}

1. Lafarga, T. Cultured Microalgae and Compounds Derived Thereof for Food Applications: Strain Selection and Cultivation, Drying, and Processing Strategies. Food Rev. Int. 2020, 36, 559-583. [CrossRef]

2. Lafarga, T. Effect of microalgal biomass incorporation into foods: Nutritional and sensorial attributes of the end products. Algal Res. 2019, 41, 101566. [CrossRef]

3. Harvey, P.J.; Ben-Amotz, A. Towards a sustainable Dunaliella salina microalgal biorefinery for 9-cis $\beta$-carotene production. Algal Res. 2020, 50, 102002. [CrossRef]

4. Gong, M.; Bassi, A. Carotenoids from microalgae: A review of recent developments. Biotechnol. Adv. 2016, 34, 1396-1412. [CrossRef]

5. Villaró, S.; Ciardi, M.; Morillas-españa, A.; Sánchez-zurano, A.; Acién-fernández, G.; Lafarga, T. Microalgae Derived Astaxanthin: Research and Consumer Trends and Industrial Use as Food. Foods 2021, 10, 2303. [CrossRef]

6. AECOSAN. Report of the Scientific Committee of the Spanish Agency for Food Safety and Nutrition on a request for initial assessment for marketing of the marine microalgae Tetraselmis chuii under Regulation (EC) No 258/97 on novel foods and novel food ingredients. Rev. Del Com. Científico 2017, 25, 1-10.

7. García, J.L.; de Vicente, M.; Galán, B. Microalgae, old sustainable food and fashion nutraceuticals. Microb. Biotechnol. 2017, 10, 1017-1024. [CrossRef] [PubMed] 
8. Vizcaíno, A.J.; López, G.; Sáez, M.I.; Jiménez, J.A.; Barros, A.; Hidalgo, L.; Camacho-Rodríguez, J.; Martínez, T.F.; Cerón-García, M.C.; Alarcón, F.J. Effects of the microalga Scenedesmus almeriensis as fishmeal alternative in diets for gilthead sea bream, Sparus aurata, juveniles. Aquaculture 2014, 431, 34-43. [CrossRef]

9. Navarro-López, E.; del Carmen Cerón-García, M.; López-Rodríguez, M.; Acién-Fernández, F.G.; Molina-Grima, E. Biostimulants obtained after pilot-scale high-pressure homogenization of Scenedesmus sp. grown in pig manure. Algal Res. 2020, $52,102123$. [CrossRef]

10. Lu, Y.; Xu, J. Phytohormones in microalgae: A new opportunity for microalgal biotechnology? Plant Physiol. 2015, 20, 273-282. [CrossRef]

11. Barceló-Villalobos, M.; Guzmán Sánchez, J.L.; Martín Cara, I.; Sánchez Molina, J.A.; Acién Fernández, F.G. Analysis of mass transfer capacity in raceway reactors. Algal Res. 2018, 35, 91-97. [CrossRef]

12. Banerjee, S.; Ramaswamy, S. Dynamic process model and economic analysis of microalgae cultivation in open raceway ponds. Algal Res. 2017, 26, 330-340. [CrossRef]

13. Granado-Lorencio, F.; Herrero-Barbudo, C.; Acién-Fernández, G.; Molina-Grima, E.; Fernández-Sevilla, J.M.; Pérez-Sacristán, B.; Blanco-Navarro, I. In vitro bioaccesibility of lutein and zeaxanthin from the microalgae Scenedesmus almeriensis. Food Chem. 2009, 114, 747-752. [CrossRef]

14. Morillas-España, A.; Lafarga, T.; Sánchez-Zurano, A.; Acién-Fernández, F.G.; Rodríguez-Miranda, E.; Gómez-Serrano, C.; González-López, C.V. Year-long evaluation of microalgae production in wastewater using pilot-scale raceway photobioreactors: Assessment of biomass productivity and nutrient recovery capacity. Algal Res. 2021, 60, 102500. [CrossRef]

15. Morillas-España, A.; Lafarga, T.; Acién-Fernández, F.G.; Gómez-Serrano, C.; González-López, C.V. Annual production of microalgae in wastewater using pilot-scale thin-layer cascade photobioreactors. J. Appl. Phycol. 2021, 1, 3861-3871. [CrossRef]

16. Garrido-Cardenas, J.A.; Manzano-Agugliaro, F.; Acien-Fernandez, F.G.; Molina-Grima, E. Microalgae research worldwide. Algal Res. 2018, 35, 50-60. [CrossRef]

17. Sánchez, J.F.; Fernández, J.M.; Acién, F.G.; Rueda, A.; Pérez-Parra, J.; Molina, E. Influence of culture conditions on the productivity and lutein content of the new strain Scenedesmus almeriensis. Process Biochem. 2008, 43, 398-405. [CrossRef]

18. Sánchez, J.F.F.; Fernández-Sevilla, J.M.M.; Acién, F.G.G.; Cerón, M.C.C.; Pérez-Parra, J.; Molina-Grima, E. Biomass and lutein productivity of Scenedesmus almeriensis: Influence of irradiance, dilution rate and temperature. Appl. Microbiol. Biotechnol. 2008, 79, 719-729. [CrossRef]

19. Morillas-España, A.; Lafarga, T.; Gómez-Serrano, C.; Acién-Fernández, F.G.; González-López, C.V. Year-long production of Scenedesmus almeriensis in pilot-scale raceway and thin-layer cascade photobioreactors. Algal Res. 2020, 51, 102069. [CrossRef]

20. Perera, E.; Sánchez-Ruiz, D.; Sáez, M.I.; Galafat, A.; Barany, A.; Fernández-Castro, M.; Vizcaíno, A.J.; Fuentes, J.; Martínez, T.F.; Mancera, J.M.; et al. Low dietary inclusion of nutraceuticals from microalgae improves feed efficiency and modifies intermediary metabolisms in gilthead sea bream (Sparus aurata). Sci. Rep. 2020, 10, 18676. [CrossRef]

21. López, C.V.G.; del Carmen Cerón García, M.; Fernández, F.G.A.; Bustos, C.S.; Chisti, Y.; Sevilla, J.M.F. Protein measurements of microalgal and cyanobacterial biomass. Bioresour. Technol. 2010, 101, 7587-7591. [CrossRef]

22. García-Márquez, J.; Rico, R.M.; Del Pilar Sánchez-Saavedra, M.; Gómez-Pinchetti, J.L.; Acién, F.G.; Figueroa, F.L.; Alarcón, F.J.; Moriñigo, M.Á.; Abdala-Díaz, R.T. A short pulse of dietary algae boosts immune response and modulates fatty acid composition in juvenile Oreochromis niloticus. Aquac. Res. 2020, 51, 4397-4409. [CrossRef]

23. Wellburn, A.R. The Spectral Determination of Chlorophylls a and b, as well as Total Carotenoids, Using Various Solvents with Spectrophotometers of Different Resolution. J. Plant Physiol. 1994, 144, 307-313. [CrossRef]

24. BOE Métodos Oficiales de Análisis: Suelos y Aguas. 1982. Available online: https://www.boe.es/diario_boe/txt.php?id=BOE-A1976-6778 (accessed on 10 January 2022).

25. Sánchez-Zurano, A.; Morillas-España, A.; Gómez-Serrano, C.; Ciardi, M.; Acién, G.; Lafarga, T. Annual assessment of the wastewater treatment capacity of the microalga Scenedesmus almeriensis and optimisation of operational conditions. Sci. Rep. 2021, 11, 21651. [CrossRef] [PubMed]

26. Tran, K.C.; Mendoza Martin, J.L.; Heaven, S.; Banks, C.J.; Acien Fernandez, F.G.; Molina Grima, E. Cultivation and anaerobic digestion of Scenedesmus spp. grown in a pilot-scale open raceway. Algal Res. 2014, 5, 95-102. [CrossRef]

27. Del Mar Morales-Amaral, M.; Gómez-Serrano, C.; Acién, F.G.; Fernández-Sevilla, J.M.; Molina-Grima, E. Outdoor production of Scenedesmus sp. in thin-layer and raceway reactors using centrate from anaerobic digestion as the sole nutrient source. Algal Res. 2015, 12, 99-108. [CrossRef]

28. Maroušek, J.; Maroušková, A. Economic Considerations on Nutrient Utilization in Wastewater Management. Energies 2021, 14, 3468. [CrossRef]

29. Murchie, E.H.; Lawson, T. Chlorophyll fluorescence analysis: A guide to good practice and understanding some new applications. J. Exp. Bot. 2013, 64, 3983-3998. [CrossRef] [PubMed]

30. He, Q.; Yang, H.; Wu, L.; Hu, C. Effect of light intensity on physiological changes, carbon allocation and neutral lipid accumulation in oleaginous microalgae. Bioresour. Technol. 2015, 191, 219-228. [CrossRef]

31. Tan, L.; $\mathrm{Xu}, \mathrm{W} . ; \mathrm{He}, \mathrm{X} . ;$ Wang, J. The feasibility of $\mathrm{F}_{\mathrm{v}} / \mathrm{F}_{\mathrm{m}}$ on judging nutrient limitation of marine algae through indoor simulation and in situ experiment. Estuar. Coast. Shelf Sci. 2019, 229, 106411. [CrossRef] 
32. Gan, T.; Zhao, N.; Yin, G.; Chen, M.; Wang, X.; Liu, J.; Liu, W. Optimal chlorophyll fluorescence parameter selection for rapid and sensitive detection of lead toxicity to marine microalgae Nitzschia closterium based on chlorophyll fluorescence technology. $J$. Photochem. Photobiol. B Biol. 2019, 197, 111551. [CrossRef]

33. Acién Fernández, F.G.; Hall, D.O.; Cañizares Guerrero, E.; Krishna Rao, K.; Molina Grima, E. Outdoor production of Phaeodactylum tricornutum biomass in a helical reactor. J. Biotechnol. 2003, 103, 137-152. [CrossRef]

34. Sánchez-Zurano, A.; Lafarga, T.; del Mar Morales-Amaral, M.; Gómez-Serrano, C.; Fernández-Sevilla, J.M.; Acién-Fernández, F.G.; Molina-Grima, E. Wastewater treatment using Scenedesmus almeriensis: Effect of operational conditions on the composition of the microalgae-bacteria consortia. J. Appl. Phycol. 2021, 1, 3885-3897. [CrossRef]

35. Sánchez-Zurano, A.; Rodríguez-Miranda, E.; Guzmán, J.L.; Acien-Fernandez, F.G.; Fernandez-Sevilla, J.M.; Molina-Grima, E. ABACO: A new model of microalgae-bacteria consortia for biological treatment of wastewater. Appl. Sci. 2021, 11, 998. [CrossRef]

36. Huesemann, M.; Crowe, B.; Waller, P.; Chavis, A.; Hobbs, S.; Edmundson, S.; Wigmosta, M. A validated model to predict microalgae growth in outdoor pond cultures subjected to fluctuating light intensities and water temperatures. Algal Res. 2016, 13, 195-206. [CrossRef]

37. Collao, J.; del Mar Morales-Amaral, M.; Acién-Fernández, F.G.; Bolado-Rodríguez, S.; Fernandez-Gonzalez, N. Effect of operational parameters, environmental conditions, and biotic interactions on bacterial communities present in urban wastewater treatment photobioreactors. Chemosphere 2021, 284, 131271. [CrossRef] [PubMed]

38. Finkel, Z.V.; Follows, M.J.; Liefer, J.D.; Brown, C.M.; Benner, I.; Irwin, A.J. Phylogenetic diversity in the macromolecular composition of microalgae. PLoS ONE 2016, 11, e0155977. [CrossRef]

39. Dickinson, K.E.; Whitney, C.G.; McGinn, P.J. Nutrient remediation rates in municipal wastewater and their effect on biochemical composition of the microalga Scenedesmus sp. AMDD. Algal Res. 2013, 2, 127-134. [CrossRef]

40. Gómez, C.; Guzmán-Carrasco, A.; Lafarga, T.; Acién-Fernández, F.G. Optimization of a new culture medium for the large-scale production of protein-rich Arthrospira platensis (oscillatoriales, cyanophyceae). J. Phycol. 2020, 27, 636-644. [CrossRef]

41. Stringham, J.M.; Bovier, E.R.; Wong, J.C.; Hammond, B.R. The influence of dietary lutein and zeaxanthin on visual performance. J. Food Sci. 2010, 75, R24-R29. [CrossRef] [PubMed]

42. Limón, P.; Malheiro, R.; Casal, S.; Acién-Fernández, F.G.; Fernández-Sevilla, J.M.; Rodrigues, N.; Cruz, R.; Bermejo, R.; Pereira, J.A. Improvement of stability and carotenoids fraction of virgin olive oils by addition of microalgae Scenedesmus almeriensis extracts. Food Chem. 2015, 175, 203-211. [CrossRef] [PubMed] 